\title{
自然每周简报
}

来源: 搜狐新闻发布

时间: 2020 年 06 月 17 日

\section{nature research}

https://news.tianyancha.com/II_v9wmnfquux.html 


\section{“猫王”蠕虫 | 缺觉不仅会伤脑 | 太空种植还得靠人类 排泄物 | 自然每周简报 _企业头条}

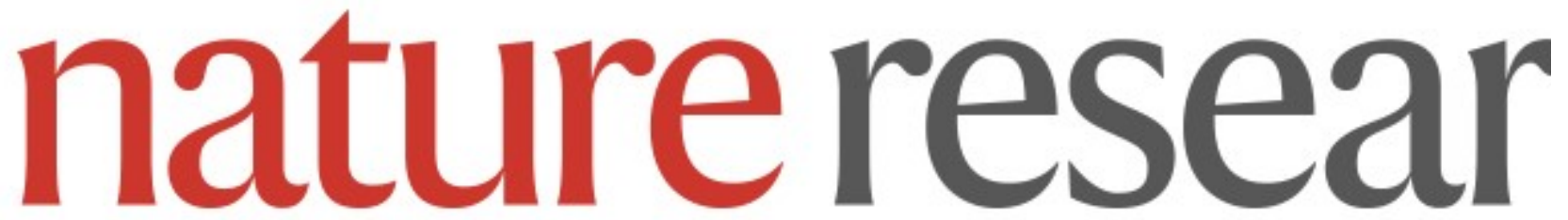

打开APP，查看更多精彩图片

自然每周简报2020年6月16日第34期

亲爱的读者们:

今天的自然简报里，你能看到以“猫王”命名的深海蠕虫，它们和蝶蚓有着远亲关系； 想要在太空种菜，“有味道”的肥料是不可或缺的；不用掘地三尺，科学家找到了画 出古罗马城市地图的方法。

最新资讯

\section{1.类胚胎结构首次揭秘人类胚胎的早期发育特征}




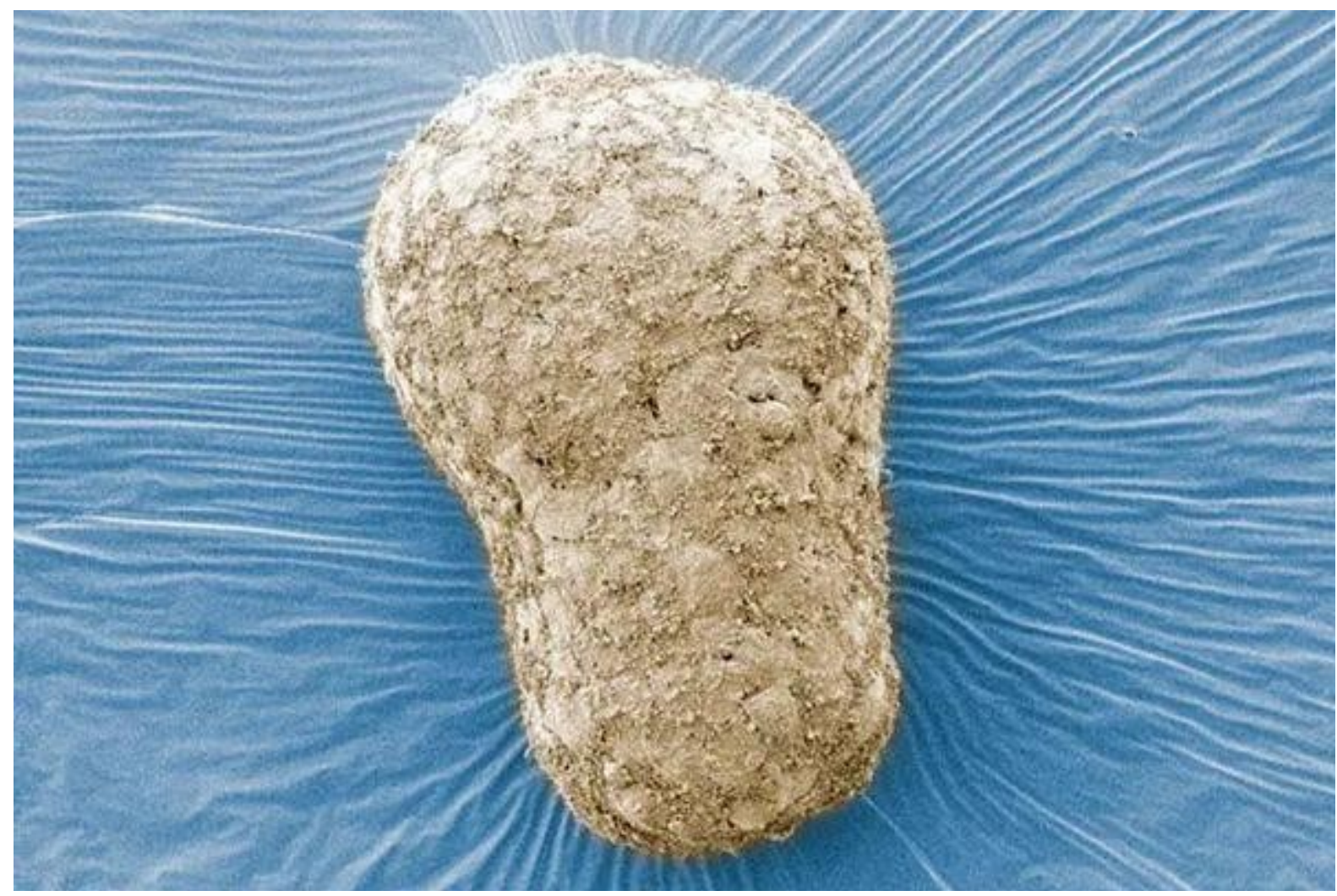

研究成员构建出了基于干细胞的三维类胚胎结构，首次展现了胚胎发育 21 天左右时 的特征。 (Naomi Moris)

类原肠肧一一由干细胞产生的三维类胚胎结构一一首次展示了人类胚胎早期的发育特 征。类原肠胚能够发育出心脏和神经系统的基本组成部分，但因为缺之必要细胞类 型，无法发育成大脑或胎儿。类胚胎结构避免了人类胚胎研究的伦理争议，有助于 揭示流产和诸如先天性心脏病、脊柱裂等胚胎早期发育障碍的具体病因。（《自 然》期刊 |参考文献：《自然》期刊论文)

《自然》论文: An in vitro model of early anteroposterior organization during human development

长按并识别右方二维码，阅读全文 $\rightarrow$

\section{2.我们离新冠疫苗究竟还有多远}

目前有超过 135 个新冠病毒SARS-CoV-2疫苗正在研发中，但其中只有阿斯利康制药 公司和牛津大学合作开发的一款疫苗即将开始III期临床试验来验证其有效性。《纽 约时报》推出的“疫苗追踪”以可视化的方式，呈现了已进入人体试验阶段或仍处于细 胞或动物学研究阶段、但颇具前景的疫苗的研发状态。（《纽约时报》)

\section{HIVI临床研究将顺性别女性排除在外引发争议}

吉利德 (Gilead) 公司研发的可预防HIV感染的接触前预防 (PrEP) 药物，近日在 患者权益倡导者和医疗专家中引起轩然大波，因为这项药物的临床研究对象不包括 顺性别女性 (cisgender women)。这款实验药物名为“cabotegravir”，其最新临床 试验 (每两个月给予一次抗逆转录病毒注射) 仅招募顺性别男性和变性女性。此 前，美国食品药品监督管理局（FDA）批准的吉利德的另一款药品Descovy也只用于 
顺性别男性和变性女性。吉利德表示目前公司正在计划一项以顺性别女性为主要研 究对象的新临床试验。“将部分女性排除在外，艾滋病永远不可能被终结。”公益倡导 组织SisterLove的创始人Dazon Dixon Diallo说。（《连线》杂志）

\section{4.缺乏睡眠影响的不仅仅是你的大脑}

果蝇被剥夺睡眠后，其肠道细胞内会积聚有毒分子，破坏细胞DNA。被剥夺睡眠的 小鼠体内也发现了类似的毒素。抗氧化剂能够减轻被剥夺睡眠的果蝇体内的毒素堆 积，使其获得正常寿命。“它们还活着! ’它们不仅活着，而且看上去活得还不错。” 发育神经学家Dragana Rogulja说。研究结果表明，尽管大部分睡眠研究都以大脑为 主要研究对象，但缺乏睡眠还会损伤其他器官，进而影响个体健康。（Quanta杂志 |参考文献：《细胞》杂志论文)

\section{IBM将停止出售“一般用途”的面部识别技术}

IBM首席执行官Arvind Krishna在给美国国会的信件中写道，IBM将不再出售“一般 用途”的面部识别技术。信中强调要解决种族不平等问题，亟需改革及政策调整，并 提到IBM公司反对通过科学技术进行大规模监视、种族形象定性和侵犯人权的行 为。Krishna写道: “人工智能 (AI) 系统的供应商和用户应共同承担起责任，确保 AI系统中没有歧视，特别是当其用于执法行动时。” (The Verge网站)

\section{6.无需掘地三尺就能绘制古罗马城市的地图}

考古学家利用探地雷达把一座古城完整地绘制了出来。Falerii Novi是罗马附近一个 占地30公顷的定居点，公元前241年至公元700年间有人居住，但现在几乎全部被掩 埋在农业用地下。一支考古学团队用四轮摩托拖着雷达天线进行探测。他们的发现 包括一个神秘的公共纪念碑一一可能与前罗马宗教有关，以及一个显然是在城市建成 之前做了规划并铺设的大规模水管网络。考古学家Martin Millett说，这种非侵入性 技术具有很大的潜力，“当我在罗马帝国的土地上徘徊，看到各种各样的地方时，我 就会想，“哇，我们可以在那里做些什么。”（《卫报》|参考文献：Antiquity期刊论 文)

\section{7.珊瑚珊瑚：如何才能拯救你}

为了帮助珊瑚适应气候变化导致的更热、更酸的海洋环境，研究人员正在探索终极 保护措施。例如，佛罗里达礁岛群 (Florida Keys) 的科学家们正在尝试通过人工饲 养珊瑚样本，维系珊瑚礁系统，这些样本都是污染逐渐加重、温度逐渐升高的自然 环境下的幸存者。另外，扩大海洋保护区也可以帮助为这些“水下森林”以及依赖它们 生存的野生生物争取时间。但是科学家强调，这些创新保护措施是远远不够的，除 非全球各国领导人采取紧急行动，减缓全球变暖的速度。(《国家地理》)

\section{8.“有味道”的太空农业入门工具包}

自航天时代一开始，研究人员就致力于研究人类在太空或在另一个星球上长期生存 所需要的条件，他们甚至在国际空间站上种植了生菜，并让种子在月球上发了芽。 专家们常常承认他们会从科幻小说中寻求灵感，说保存人类排泄物作为肥料至关重 要。“那就相当于一个入门工具包，开启土壤种植的入门工具包。”生态学家Wieger Wamelink说，“实际上，《火星救援》在这点上是完全正确的。粪便可能有点臭， 但它们确实不可或缺。” (《卫报》) 


\section{9.四项信息让撤稿更透明}

去年，科学数据管理研究人员Quan-Hoang Vuong分析了 2,000 多个撤稿通知，发现 其中大部分对于撤稿原因只是粗略带过，大约 $10 \%$ 的撤稿则完全没有提到理由。 Vuong建议所有的撤稿通知都包括以下四项信息：撤稿发起人、撤稿原因、编辑和 作者之间是否就此达成共识、撤稿是否涉及发表后审查。（《自然》期刊）

《自然》: Reform retractions to make them more transparent 长按并识别右方二维码，阅读全文 $\rightarrow$ 本月科技图片

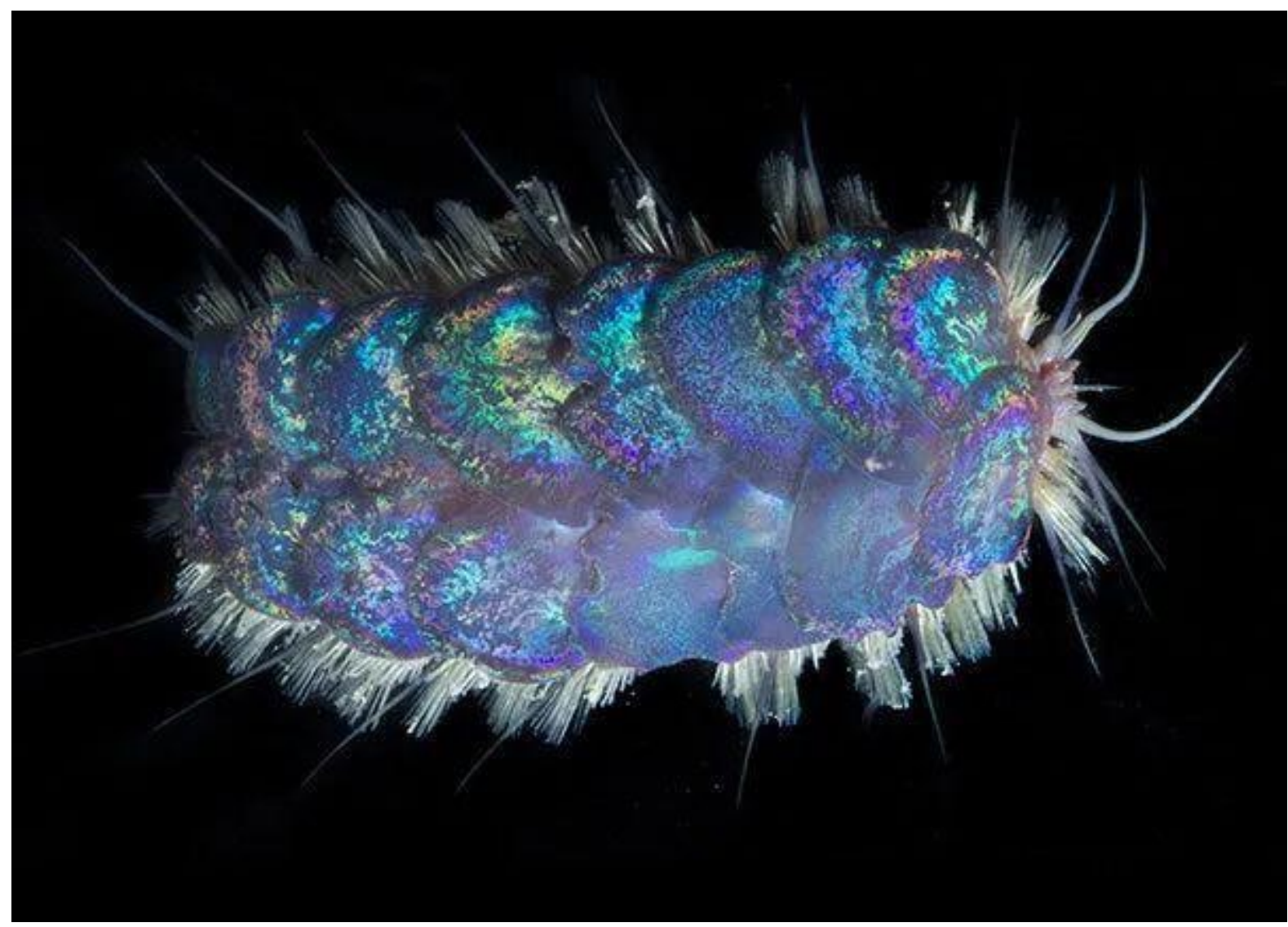

这是新近发现的一种深海蠕虫Peinaleopolynoe elvisi，因其五彩斑刘速的鳞片令人联想 起音乐巨星Elvis Presley满是亮片的连体裤而得名。科研人员借助一艘载人研究潜艇 和多个遥控潜水器，从东太平洋底部、墨西哥湾和哥斯达黎加附近区域收集到了四 个这样令人惊叹的物种。通过DNA测序，研究人员将这四个新发现物种归于 Peinaleopolynoe属，这是一类与蚯蚓有远亲关系的有鳞蠕虫。（《自然》）

《自然》: Murder hornets, park robots and planet formation - May's best science images

长按并识别右方二维码，阅读全文 $\rightarrow$

\section{英文版Nature Briefing}

每个工作日，您的邮箱都能收到由自然科研高级编辑撰写，客观而独立，为科研群 
体量身定制，精选来自《自然》和其他全球资讯平台的最新、最具价值的内容。

\section{如何订阅:}

前往Go.nature.com/wechat或长按右侧二维码即可订阅

网页端查看:

点击い下方“查看原文”即可直接查看英文官网。

声明: 本文转载自于搜狐新闻，目的在于传递信息，并不代表本网赞同其观点和对 其真实性负责；如涉及内容侵权、投诉、内容接入合作等问题，请邮件至 feedback@tianyancha.com 


\section{References:}

David Cyranoski (2020). Lab-grown cells mimic crucial moment in embryo development. Nature, 582, 325. doi:10.1038/d41586-020-01757-z

Alexandra Witze (2020). Astronomers spot first fast radio burst in the Milky Way. Nature, 582, 322323. doi: 10.1038/d41586-020-01666-1

Michele Cohen Marill (2020). The Dangers of Excluding Women From HIV Prevention Drug Tests. WIRED. https://www.wired.com/story/the-dangers-of-excluding-women-from-hiv-preventiondrugtests/

Jonathan Corum, Denise Grady, Sui-Lee Wee, and Carl Zimmer (2020). Coronavirus Vaccine Tracker. New York Times. https://www.nytimes.com/interactive/2020/science/coronavirusvaccinetracker.html

Ann Reid (2020). Advocacy works, but more must be done to protect against misinformation. Nature, 582, 315. doi:10.1038/d41586-020-01454-x

George Ellis (2020). From chaos to free will. Aeon (June 9). https://aeon.co/essays/heres-why-somanyphysicists-are-wrong-about-free-will

Ryan Hanna, Yangyang Xu, \& David G. Victor (2020). After COVID-19, green investment must deliver jobs to get political traction. Nature, 582, 178-180. doi:10.1038/d41586-020-01682-1

Quan-Hoang Vuong (2020). Reform retractions to make them more transparent. Nature, 582, 149. doi:10.1038/d41586-020-01694-x 